\title{
C677T and A1298C gene polymorphisms and sporadic early-onset Alzheimer's disease
}

\author{
Leila Mansouri $^{1}$, Sarra Klai ${ }^{1 *}$, Najiba Fekih-Mrissa ${ }^{1}$, Nasreddine Gritlii ${ }^{1}$, Ridha Mrissa ${ }^{2}$ \\ ${ }^{1}$ Laboratory of Molecular Biology, Department of Hematology, Military Hospital, Tunis, Tunisia; \\ *Corresponding Author: gksarrah@yahoo.fr \\ ${ }^{2}$ Department of Neurology, Military Hospital, Tunis, Tunisia
}

Received 18 August 2013; revised 27 September 2013; accepted 9 October 2013

Copyright (C) 2013 Leila Mansouri et al. This is an open access article distributed under the Creative Commons Attribution License, which permits unrestricted use, distribution, and reproduction in any medium, provided the original work is properly cited.

\begin{abstract}
Alzheimer's disease (AD) is a genetically complex and heterogeneous disorder. Although the clinical manifestations and the pathological features have been well elucidated, a clear etiology of $A D$ is still unknown to this day. In the past few decades, investigations have elucidated that both the genetic and the environmental factors are capable of causing the development of AD. We report a patient with clinically diagnosed earlyonset Alzheimer's disease, age of onset 45 years. Genetic analysis revealed two MTHFR heterozygous polymorphisms C677T and A1298C.
\end{abstract}

Keywords: A1298C MTHFR Mutation; C677T MTHFR Mutation; Early-Onset Alzheimer

\section{INTRODUCTION}

Alzheimer is the first common cause of dementia [1]. Classification of Alzheimer's disease (AD) into subtypes based on the time of onset of the symptoms is still controversial. Clinically, late-onset patients with $\mathrm{AD}$ have a greater degree of memory disturbance, while early-onset patients have greater degrees of other cognitive dysfunctions and a rapid progression of cognitive deficits rather than memory disturbance in the early stage of the disease [2].

The genetic determinants of early-onset $(<65$ years of age) Alzheimer's disease (EOAD) are heterogeneous. [3] The term early onset (EO) Alzheimer's disease (AD) refers to patients who meet the criteria for $\mathrm{AD}$ [4] and show onset of symptoms before the age of 65 years. Compared with the more frequent late onset (LO) $\mathrm{AD}, \mathrm{EOAD}$ patients present with a more rapid clinical and cognitive decline and an earlier multidomain cognitive impairment, including language, visuospatial, and executive function deficits .[5]

The role of methylenetetrahydrofolate reductase (MTHFR) gene polymorphisms as risk factors for the occurrence of Alzheimer's disease (AD) is still controversial. A common $\mathrm{C} \rightarrow \mathrm{T}$ polymorphism at position 677 in the methylenetetrahydrofolate reductase gene (MTHFR) has been recently studied and proposed as $\mathrm{AD} /$ dementia risk factor [6].

\section{CASE REPORT}

We describe a 53-year-old man diagnosed with very rapidly progressing early-onset Alzheimer's disease (EOAD), age of onset 45 years, and two MTHFR polymorphism C677T and A1298C were detected. A rapidly progressive neuropsychological deterioration associated with motor deficits and cerebellar signs dominated the clinical picture. There's no family history of AD disease.

The patient presented a progressive alteration of episodic memory, spatial disorientation, apathy, language disturbances and neglect of personal care. At 45 years, he had begun to have episodic memory problems. His wife reported forgetfulness (losing objects and forgetting meetings, conversations, and receipts), diminished language fluency and word-finding difficulties.

\subsection{Neuropsychological Assessment}

Neuropsychological investigation assessed: global cognitive functioning, visuospatial functions, frontal-executive functions, and learning with Rey's word list immediate and delayed recall [4].

\subsection{Genetic Analysis}

Blood $(6 \mathrm{~mL})$ was collected in ethylenediaminetetraacetic acid (EDTA) vial. Genomic DNA was extracted from the leukocytes in the cell pellet by salting out method [7]. The polymerase chain reaction (PCR) was used 
to type the thermolabile methylene tetrahydropholate reductase (MTHFR) C677T and A1298C polymorphism. After amplification, the PCR product underwent a reverse hybridization. Heterozygous C677T and A1298C mutations were detected.

\section{DISCUSSION}

This patient with early-onset Alzheimer's disease (EOAD) was reported to be different from those with late onset Alzheimer's disease (LOAD) in terms of neuropsychological and neuroimaging findings. Patients with EOAD tend to display more diverse cognitive impairments and neurological deficits than those with LOAD, such as language, visuospatial, and executive dysfunctions [8,9], and extrapyramidal signs, whereas patients with LOAD present cognitive impairment of the amnesia-predominant type [10].

Approximately $10 \%$ of cases present at an age of onset before 65 years old, which in turn can bemonogenic familial AD (FAD) or sporadic early-onset $\mathrm{AD}$ (EOAD) [11].

In the past few decades, investigations have elucidated that both the genetic and the environmental factors are capable of causing the development of AD.

5,10-Methylenetetrahydrofolate reductase (MTHFR) is an important enzyme in the pathway of regulation of homocysteine (Hcy) concentrations. It can catalyze the conversion of 5,10-methylenetetrahydrofolate to 5-methyltetrahydrofolate, which is the predominant form of folate in plasma and provides the methyl group for methionine synthesis through homocysteine remethylation. The experiment proved that the homozygous mutations of the MTHFR gene, $\mathrm{C} \rightarrow \mathrm{T}$ transition at nucleotide position 677, could decrease the enzymatic activity and cause elevation of Hcy level [12]. Significant association between hyperhomocysteinaemia, MTHFR C677T polymorphism and cardiovascular diseases risk has been identified $[13,14]$.

Since hyperhomocysteinaemia is regarded as a risk factor of atherosclerotic disease, it may also play an important role in the development of AD [15]. A large number of small, individually underpowered, case-control studies have been performed to assess the associations between MTHFR C677T polymorphism and AD. However, the results remain conflicting in many ethnies: Italy, England, Brazile and other countries [16]. In the subgroup analysis of ethnicity, The results showed that MTHFR 677T had an effect of increasing the AD risk for all model comparisons in East Asians, while no evidence of association between MTHFR C677T polymorphisms and AD was observed in Caucasians [17]. On the other hand there is little known about the A1298C MTHFR mutation, there are no studies in the literature that addresses the relationship between this mutation and AD.
The role of methylenetetrahydrofolate reductase (MTHFR) gene polymorphisms as risk factors for the occurrence of Alzheimer's disease (AD) is still controversial. A relatively new approach to the pathogenesis of Alzheimer's disease (AD), a typical multifactorial disease, warrants the study of the interplay between classic $\mathrm{AD}$ risk factors and a number of other contributors causing brain damage by various mechanisms. Among emerging probable contributors, vascular risk factors [18-20] seem to play an important role.

Despite these seminal advances in understanding the genetics and pathophysiology of early-onset familial AD, several lines of evidence suggest that additional genetic factors remain to be identified for this form of the disease. This will then enable a strategy for "early prediction and early prevention" of AD, which forms the cornerstone of genomic medicine [21].

\section{CONCLUSION}

The absence of effective prophylactic treatments for AD limits presymptomatic and antenatal testing for ethical reasons (Hedera, 2001). However, if any of the experimental prevention or treatment strategies proves to be effective, molecular diagnosis in risk families will become very important. Knowledge gained from genetic studies of $\mathrm{AD}$ was and remains the essential prerequisite for our current understanding of the etiological and pathophysiological mechanisms leading to neurodegeneration in $\mathrm{AD}$ as well as for the development of novel strategies for the treatment and prevention of this disease.

\section{REFERENCES}

[1] Liu, H., Yang, M., Li, G.M., et al. (2010) The MTHFR C677T polymorphism contributes to an increased risk for vascular dementia: A meta-analysis. Journal of the Neurological Sciences, 294, 74-80. http://dx.doi.org/10.1016/j.jns.2010.04.001

[2] Sakamoto, S., Ishii, K., Sasaki, M., et al. (2002) Differences in cerebral metabolic impairment between early and late onset types of Alzheimer's disease. Journal of the Neurological Sciences, 200, 27-32. http://dx.doi.org/10.1016/S0022-510X(02)00114-4

[3] Zekanowski, C., Styczyńska, M., Peplońska, B., et al. (2003) Mutations in presenilin 1, presenilin 2 and amyloid precursor protein genes in patients with early-onset Alzheimer's disease in Poland. Experimental Neurology, 184, 991-996.

http://dx.doi.org/10.1016/S0014-4886(03)00384-4

[4] Canua, E., Frisoni, G.B., Agosta, F., et al. (2012) Early and late onset Alzheimer's disease patients have distinct patterns of white matter damage. Neurobiology of Aging, 33, 1023-1033.

http://dx.doi.org/10.1016/j.neurobiolaging.2010.09.021 
[5] Rogaeva, E. (2002) The solved and unsolved mysteries of the genetics of early-onset Alzheimer's disease. NeuroMolecular Medicine, 2, 1-10. http://dx.doi.org/10.1385/NMM:2:1:01

[6] Seripa, D., Dal Forno, G., Matera, G., et al. (2003) Methylenetetrahydrofolate reductase and angiotensin converting enzyme gene polymorphisms in two genetically and diagnostically distinct cohort of Alzheimer patients. Neurobiology of Aging, 24, 933-939. http://dx.doi.org/10.1016/S0197-4580(03)00040-X

[7] Miller, S.A., Dykes, D.D. and Polesky, H.S. (1998) Simple salting out procedure for extracting DNA from human nucleated cells. Nucleic Acids Research, 16, 1215. http://dx.doi.org/10.1093/nar/16.3.1215

[8] Mendez, M.F., Lee, A.S., Joshi, A. and Shapira, J.S. (2012) Nonamnestic presentations of early-onset Alzheimer's disease. American Journal of Alzheimer's Disease and Other Dementias, 27, 413-420.

[9] Smits, L.L., Pijnenburg, Y.A., Koedam, E.L., van der Vlies, A.E., Reuling, I.E., Koene, T., Teunissen, C.E., Scheltens, P. and van der Flier, W.M. (2012) Early onset Alzheimer's disease is associated with a distinct neuropsychological profile. Journal of Alzheimer's Disease, 30, 101-108.

[10] Cho, H., Seo, S.W., Kim, J.-H., et al. (2013) Changes in subcortical structures in early-versus late-onset Alzheimer's disease. Neurobiology of Aging, 34, 1740-1747.

[11] Antonell, A.L. and Altirriba, J., et al. (2013) A preliminary study of the whole-genome expression profile of sporadic and monogenic early-onset Alzheimer's disease. Neurobiology of Aging, 34, 1772-1778.

[12] Isotalo, P.A., Wells, G.A. and Donnelly, J.G. (2000) Neonatal and fetal methylenetetrahydrofolate reductase genetic polymorphisms: An examination of C677T and A1298C mutations. The American Journal of Human Genetics, 67, 986-990.

[13] Humphrey, L.L., Fu, R., Rogers, K., Freeman, M. and Helfand, M. (2008) Homocysteine level and coronary heart disease incidence: A systematic review and metaanalysis. Mayo Clinic Proceedings, 83, 1203-1212. http://dx.doi.org/10.4065/83.11.1203
[14] Klerk, M., Verhoef, P., Clarke, R., Blom, H.J., Kok, F.J., Schouten, E.G. and MTHFR Studies Collaboration Group (2002) MTHFR $677 \mathrm{C} \rightarrow \mathrm{T}$ polymorphism and risk of coronary heart disease: A meta-analysis. JAMA, 288, 20232031. http://dx.doi.org/10.1001/jama.288.16.2023

[15] Seshadri, S., Beiser, A., Selhub, J., Jacques, P.F., Rosenberg, I.H., D'Agostino, R.B., Wilson, P.W. and Wolf, P.A. (2002) Plasma homocysteine as a risk factor for dementia and Alzheimer's disease. The New England Journal of Medicine, 46, 476-483. http://dx.doi.org/10.1056/NEJMoa011613

[16] Copede, F. (2010) One-carbon metabolism and Alzheimer's disease: Focus on epigenetics. Current Genomics, 14, 246-260. http://dx.doi.org/10.2174/138920210791233090

[17] Zhanga, M.Y., Miaoa, L., Li, Y.-S., et al. (2012) Metaanalysis of the methylenetetrahydrofolate reductase C677T polymorphism and susceptibility to Alzheimer's disease. Neuroscience Research, 68, 142-150. http://dx.doi.org/10.1016/j.neures.2010.06.011

[18] Bertram, L. and Tanzi, R.E. (2003) Genetics of Alzheimer's disease. In: Dickson, D.W., Ed., Neurodegeneration: The Molecular Pathology of Dementia and Movement Disorders, ISN Neuropath Press, Basel, 40-46.

[19] Olson, J.M., Goddard, K.A. and Dudek, D.M. (2002) A second locus for very-late-onset Alzheimer disease: A genome scan reveals linkage to $20 \mathrm{p}$ and epistasis between $20 \mathrm{p}$ and the amyloid precursor protein region. The American Journal of Human Genetics, 71, 154-161. http://dx.doi.org/10.1086/341034

[20] Bertram, L., Blacker, D., Crystal, A., Mullin, K., Keeney, D., Jones, J., et al. (2000) Candidate genes showing no evidence for association or linkage with Alzheimer's disease using family-based methodologies. Experimental Gerontology, 35, 1353-1361. http://dx.doi.org/10.1016/S0531-5565(00)00193-5

[21] Bertram, L. and Tanzi, R.E. (2004) The current status of Alzheimer's disease genetics: What do we tell the patients? Pharmacological Research, 50, 385-396. http://dx.doi.org/10.1016/i.phrs.2003.11.018 